\title{
CONGRESO DE LA FEDERACION INTERNACIONAL DE LA VIVIENDA Y URBANISMO. SEPTIEMBRE DE 1973. URBANISMO Y DEMOCRACIA
}

$71(061.3)$

\author{
Por \\ Enrique Jardí Casany \\ Doctor en Derecho, Abogado del Ilustre Colegio de Barcelona
}

SUMARIO: I. UNA CUESTION APASIONANTE.-II. VENTAJAS E INCONVENIENTES.-III. CONCILIACION DE LAS ACTITUDES EXTREMAS.-IV. LA LEGISLACION ESPAÑOLA.

\section{UNA CUESTION APASIONANTE}

Del 9 al 14 de septiembre de 1973 se celebró en Copenhague un congreso organizado por la Federación Internacional de la Vivienda y Urbanismo, I. F. H.P., F. I. H. U. A. T. o I. V.W.S. R. en las siglas según se emplee, respectivamente, el inglés, francés o alemán, que son las tres lenguas oficiales de esa federación continuadora de la entidad fundada en 1913 por Ebenezer Howard para proteger la idea de las ciudades-jardín.

Un congreso convocado por la misma entidad tuvo lugar en mayo de 1970 en Barcelona.

Para el reunido en la capital danesa se había propuesto como materia de debate la cuestión de la estructura de los poderes locales y la planificación del medio ambiente, materia que se dividió en los cuatro temas siguientes:

1. Análisis de las estructuras administrativas para la ejecución de los planes. 
2. Tentativas de mejora de los medios administrativos (en el plano teórico).

3. Tentativas de mejora de los medios administrativos (en la práctica).

4. Participación e iniciativa del público.

Ejemplos muy interesantes de participación de los ciudadanos en la planificación fueron citados por congresistas del Reino Unido, de Austria y de Dinamarca, pero sobre todo de los Estados Unidos, quienes explicaron cómo en algunas de cuyas ciudades 0 condados metropolitanos funcionan "comités consultivos de habitantes" de composición numerosa (en ciertos casos, hasta de 300 miembros) que asesoran y a menudo impulsan a las autoridades en materia urbanística. Incluso un asistente al congreso procedente de la República Democrática Alemana expuso un caso concreto, el de Rostock, cuya administración comunal había ido informando a los ciudadanos - aunque no compulsando su opinión- sobre el proceso de urbanización de nuevos barrios.

Las discusiones surgidas en las reuniones programadas para el examen del tema cuarto fueron muy vivas, y en el curso de los debates de los restantes esta cuestión de la participación del público fue planteada insistentemente por los congresistas. Puede decirse que, de hecho, fue el problema que más apasionó a los participantes, al punto que el secretariado del congreso, en el momento de redactar las conclusiones adoptadas, a pesar de ser aquél un aspecto muy secundario de la materia objeto de la reunión, creyó que debía incluir, entre las sugerencias o reformas a introducir en la legislación de los países dispuestos a acordar una potenciación de las facultades de las entidades locales en la planificación del medio ambiente, la garantía de una intensa participación de los ciudadanos en el proceso planificador.

La mayor sensibilización por los problemas urbanísticos que - gradualmente adquieren al menos los habitantes de las grandes ciudades; la mayor información de la que cada día disponen más los residentes de los crecidos núcleos de población; la mayor exigencia de participar o influir en el gobierno de la comunidad, exigen que los que viven en un espacio geográfico concreto puedan determinar en un grado u otro la ordenación física del mismo.

El congreso de Copenhague ha servido para exteriorizar una inquietud cada vez más sentida en la práctica y entre los teóricos de 
lograr la democratización del urbanismo. Claro está que empleamos el término «democracia» en un sentido lato de distribución entre el mayor número de personas de las responsabilidades de gobierno y no aplicamos estrictamente las nociones de Derecho político, como hizo en la reunión de la capital de Dinamarca el rapporteur del Reino Unido M. T. Fagence de distinguir una planificación urbanística por parte del pueblo, correspondiente a la forma de democracia directa, de otras planificaciones por parte de los elegidos, de los funcionarios o de una «élite», a las que, respectivamente, atribuye la equivalencia de la democracia representativa, de la burocracia y de la aristocracia, ya que en la actual sociedad, tan tecnificada, es difícil dilucidar si el funcionario o burócrata con un grado de especialización que lo ha elevado a la categoría de planificador no forma parte de aquella «élite» que en tiempos pasados integraban la aristocracia. Además, admitiendo la existencia de una democracia indirecta, es dudoso que los representantes del pueblo puedan por sí solos planificar. A lo sumo formarán parte de órganos colegiados con funciones de supervisión o sanción de los instrumentos de planeamiento.

Quedamos, pues, que por democratización del urbanismo se entiende la participación del ciudadano al nivel que fuera en el proceso de planificación. Admitimos, no obstante, que esa intervención, que en teoría parece incuestionable, tiene sus pros y sus contras. Examinémoslas.

\section{VENTAJAS E INCONVENIENTES}

Quienes sostienen que únicamente la Administración pública debe asumir la responsabilidad del proceso urbanístico se fundan en algunos de los argumentos siguientes:

a) El poder público ostenta la soberanía territorial; del mismo modo que mantiene la intangibilidad de sus confines o reivindica porciones de su territorio bajo la soberania de otros Estados, tiene derecho a ejercer aquellas actividades que supongan una distribución del mismo, como la determinación de circunstancias o el cambio de su configuración, mediante la fijación de sus usos, que es, en definitiva, la finalidad de la planificación. 
b) El Estado vela por el bienestar de la comunidad de un modo general; se encuentra en una posición superior a aquella donde se enfrentan los intereses particulares, a menudo contrapuestos, respecto a los cuales realiza una función arbitral. Dejar la responsabilidad de la planificación, cualquiera que sea su grado, a manos de las personas privadas equivaldría a suscitar los enfrentamientos antes referidos, con el riesgo de que el Estado pudiera no resolverlos en un sentido beneficioso para toda la colectividad. Una planificación no estatal es a menudo una planificación por parte de grupos de presión que avasallan al ciudadano.

c) Sólo la Administración dispone de los medios técnicos y de los recursos económicos necesarios para planear. Entre aquellos medios debe comprenderse, incluso, el ejercicio del poder coercitivo, que sólo corresponde a la Administración pública, para obtener los datos que se precisan para la preparación del planeamiento.

d) La percepción de la voluntad de los administrados en materia urbanística, bien sea efectuando encuestas y sondajes, bien sea organizando comités mixtos de autoridades o funcionarios y vecinos, es difícil de lograr; los resultados de los sistemas que se emplean para aquella auscultación son poco garantizados $\mathrm{y}$, por otra parte, su utilización entorpece el proceso de planificación, de sí tan laborioso.

Las consultas que pueda organizar la Administración pública fácilmente se convierten en vehículos de expresión de las posturas sociales más radicales, en instrumentos de «contestación».

e) El ciudadano frente al planeamiento adopta a menudo posiciones que son más defensivas que constructivas. Se opone a la Administración simplemente. No colabora con ella.

En cambio, quienes discuten el monopolio, por parte del Estado, de las funciones urbanísticas y sobre todo la de planear aducen razones como:

f) El grado de madurez alcanzado por la sociedad, al menos en los países de civilización industrial, con medios de comunicación de masas de alcance muy amplio, exige que no se prive a los administrados de poder influir en la toma de decisiones de la Administración pública en asuntos como los relativos al urbanismo, que les afectan de un modo tan directo y consțante y sobre los que 
no precisan tener un conocimiento especializado en cuanto deban ser tomadas opciones fundamentales: remodelación, comunicaciones, zonificación, etc.

El planeamiento sin el concurso del ciudadano supone una mentalidad paternalista por parte de la Administración, ya superada en la época actual.

g) El hecho de que el proceso urbanístico sea iniciado y desarrollado por el Poder público sin la intervención del ciudadano no constituye ninguna garantía de que el interés general prevalezca sobre los particulares, ya que los grupos de presión también pueden actuar sobre los técnicos y funcionarios encargados del planeamiento, predeterminando sus decisiones.

h) El técnico o el funcionario que intervienen en el proceso planificador, por lo común desarrollado lejos de la zona objeto de planificación, no conocen sus problemas, adolecen del grave defecto de irrealismo. El ciudadano puede evitar, incluso con su crítica, que los planeadores se divorcien de la realidad.

\section{CONCILIACION DE LAS ACTITUDES EXTREMAS}

Una y otra posición pueden ser armonizadas siempre y cuando, admitiéndose la conveniencia de la participación del administrado en el planeamiento, se determine previamente qué grado de intervención debe tener en la elaboración de cada tipo de plan. Así parece que puede participar más en los barrios de distritos urbanos que en los del Municipio; en éstos más que en los comarcales o de áreas metropolitanas; en éstos más que en los departamentales o provinciales, y así sucesivamente hasta los planes nacionales o estatales, en los que la intervención del administrado deberá ser conducida por los cauces de la democracia representativa, es decir, se realizará por medio de los diputados. A mayor extensión del área del planeamiento, menor será la participación.

En segundo lugar, también parece recomendable que se restrinja al mínimo la intervención individual del ciudadano en el proceso planificador, aunque no pueda desdeñarse nunca la consulta, la encuesta o la participación por referéndum. La participación a través de comités de barrio, asociaciones de vecinos o propietarios, comu- 
nidades religiosas $\mathrm{o}$ asociaciones profesionales es evidentemente más eficaz.

Por último, deben distinguirse en la intervención del administrado o democratización del proceso de planificación urbanística los tipos de participación que sean más recomendables, puesto que aquélla puede consistir:

1. En iniciativas.

2. En formas de colaboración más o menos activas (desde la recogida de datos a la pertenencia a comisiones mixtas de trabajo o de decisión).

3. En la fiscalización de la tarea de técnicos y funcionarios.

4. En la sanción (por referéndum, por representantes en los órganos legislativos).

\section{LA LEGISLACION ESPAÑOLA}

De acuerdo con la legislación vigente en nuestro país, ¿qué oportunidades tiene el ciudadano para intervenir en el proceso planificador?

Desde luego, puede tener la iniciativa de la planificación urbanística para ámbitos reducidos, ya que el artículo 40 de la Ley del Suelo autoriza a las personas privadas para formar planes municipales, comarcales y especiales y colaborar en la ordenación urbanística del Municipio, la Comarca, la Provincia o de determinados aspectos del paisaje a través de la información pública de planes aprobados inicialmente (art. 32-1), aunque en nuestro Código de Urbanismo no hay precepto alguno relativo a la vinculación, por parte de la Corporación que en principio hubiere sancionado el plan, de las observaciones o reclamaciones formuladas durante el expresado período, ya que sólo se menciona la aprobación provisional "en vista del resultado de la información» (art. 32-2), expresión que sugiere el carácter facultativo que para el ente planificador tiene la estimación de la voluntad del particular que ha participado en aquélla.

Fuera de su intervención no vinculante en el período de información pública, el particular no promotor del planeamiento no podrá participar en el proceso planificador. No le será factible re- 
cabar la información del estado de su tramitación ni solicitar la expedición de copias de determinados extremos del expediente previstos en los artículos 62 y 63 de la Ley reguladora del Procedimiento Administrativo de 17 de julio de 1958, por cuanto el Decreto de 10 de octubre del mismo año excluye de la normativa de la Ley antes citada el procedimiento en materia de formación, aprobación y revisión y modificación de planes de urbanismo.

Claro está que podrá ejercer la acción pública ante la jurisdicción contencioso-administrativa para exigir la observancia de los planes (art. 223), pero esta fiscalización es una de las formas de participación del ciudadano en el proceso urbanístico que menos sirve para la manifestación de sus aspiraciones o intereses.

Las Corporaciones locales y organismos urbanisticos habrán de resolver las peticiones fundadas que se les dirijan con arreglo a esta Ley, dice el artículo 207 del Código del Urbanismo español. Este precepto permite realmente la exteriorización de aspiraciones del ciudadano en materia urbanística, canalizando la iniciativa particular ejercida al amparo del derecho de petición, derecho fundamental reconocido por el artículo 21 del Fuero de los Españoles y regulado por el artículo 39 de la Ley de Régimen jurídico de la Administración del Estado, de 26 del julio de 1957, y más extensamente por la Ley $92 / 1960$, de 22 de diciembre.

Con todo, debe concluirse que los medios legales para la participación de los particulares en el planeamiento son exiguos y que las reformas que en España pudieran introducirse, siguiendo la recomendación contenida en las conclusiones del congreso internacional celebrado en la capital danesa, serán muy bien acogidas por cuantos viven intensamente los problemas del urbanismo, como los lectores de esta revista. 
REVL-1974, núm. 181. JARDI CASANY, ENRIQUE. CONGRESO DE LA FEDERACION INTERNACIO... REVL-1974, núm. 181. JARDI CASANY, ENRIQUE. CONGRESO DE LA FEDERACION INTERNACIO... 
REVL-1974, núm. 181. JARDI CASANY, ENRIQUE. CONGRESO DE LA FEDERACION INTERNACIO...

REVISTA

DE

ESTUDIOS

(Ge DE LA

VIIA LOCAL

\section{ESTADISTICA}


